\title{
Potential Applications of Stem Cells in Livestock Production
}

\author{
Kennady Vijayalakshmy*, Ninan Jacob*, Dharmendra Kumar, Meenakshi Virmani, \\ Naresh Selokar Lalaji and P.S. Yadav
}
Department of Veterinary Physiology, Rajiv Gandhi Institute of Veterinary Education and Research, Kurumbapet, Puducherry, India

*Corresponding author

\section{A B S T R A C T}

\begin{tabular}{|l|}
\hline K e y w o r d s \\
$\begin{array}{l}\text { Classification, Livestock } \\
\text { Production, Plasticity, } \\
\text { Stem cells, Therapeutic } \\
\text { applications }\end{array}$ \\
\hline Article Info \\
\hline $\begin{array}{l}\text { Accepted: } \\
\text { 04 February } 2018 \\
\text { Available Online: } \\
\text { 10 March } 2018\end{array}$ \\
\hline
\end{tabular}

\section{Stem cells - properties}

Nowadays Stem cells have acquired a foremost share in all fields of research work including veterinary, agriculture, human medicine and genetic engineering. Stem cells are those cells which have two important properties which include self-renewal and differentiation (Anand et al., 2011). Selfrenewal indicates that the stem cells have the ability to undergo continuous, unlimited cell division and also maintain the undifferentiated state. The potential to differentiate (Potency) indicates that the stem cells can alter to one or several other (different) cell types under proper experimental, physiological and culture conditions.
When stem cells divide, the new daughter cell may either remain as a stem cell or may become a specialized cell (muscle cell, blood cell, nerve cell) with a particular function. A signal is needed for the Stem cells to divide and to activate the genes for differentiation into a particular cell type.

\section{Stem cells - origin and classification}

The two major categorizations of stem cells include Embryonic Stem Cells and Adult Stem Cells. Embryonic Stem cells are the one which are isolated from the Inner Cell Mass (ICM) of Embryo, whereas the Adult Stem Cells are derived from Adult Body Organs (Kumar et al., 2011). 
The cells in the embryo (blastocyst) congregate to form the Inner Cell Mass (ICM) and the Trophoblast. Embryonic stem cells (i.e. ICM) differentiate into Ectoderm, Mesoderm and Endoderm which further develop into the internal organs of the animal. The Trophoblast forms the placenta.

Organs that rise from

Ectoderm - Nervous system, Teeth, Hair, Exocrine glands, Mammary glands

Mesoderm - Muscle (Skeletal, Cardiac and Smooth), Pharyngeal arches muscle, Connective tissue, Dermis, Subcutaneous layer of skin, bone and cartilage, Dura matter, Internal Sex Organs

Endoderm - Epithelial lining of Digestive and Respiratory systems, Liver, Pancreas, the lining of the follicles of Thyroid gland, Thymic epithelial cells, the epithelium of Auditory tube and Tympanic membrane, the Urinary bladder and part of the Urethra.

Adult stem cells (Somatic stem cells) are found in juvenile or adult animals. The different types are

\section{Hemopoeitic stem cells}

Stem cells that have the ability to form all blood cells and immune cells. These cells are responsible for the constant renewal of blood by means of production of billions of new blood cells each day. They have the greatest powers of self-renewal of any adult tissue. Found in bone marrow and umbilical cord blood.

\section{Mesenchymal stem cells}

They are highly beneficial in handling various chronic and debilitating clinical conditions of canines, equines and caprines. These can be used as an attractive tool in regenerative medicine for cell therapy. They are of stromal origin. They are isolated from bone marrow, lung, adipose tissue, blood, teeth (periodontal ligament and dental pulp) and placenta.

\section{Neural stem cells}

Neural stem cell is a largely undifferentiated cell originating in the central nervous system. Neural stem cells (NSCs) have the potential to give rise to offspring cells that grow and differentiate into neurons and glial cells. Lewis (1968) first reported the presence of stem cells in mature primate brain. Altman and Das (1965) discovered that neurogenesis continues into adulthood in rats. Adult neurogenesis is restricted to two areas of the brain - the subventricular zone, which lines the lateral ventricles, and the dentate gyrus of the hippocampal formation (Alvarez-Buylla $e t$ al., 2002).

\section{Skin stem cells}

The skin constantly renews itself throughout adult life, and the hair follicle undergoes a perpetual cycle of growth and degeneration. Stem cells (SCs) residing in the epidermis and hair follicle ensure the maintenance of adult skin homeostasis and hair regeneration.

\section{Retinal stem cells}

The retina helps to perceive light by relaying electrochemical signals to the secondary neurons and visual cortex. The sources of stem cells for retinal regeneration include endogenous retinal stem cells (e.g., neuronal stem cells, Muller cells and retinal stem cells from the ciliary marginal zone).

\section{Testicular stem cells}

Multi potent stem cells have been derived from spermatogonial germ cells of the testicles in mice (Barbara, 2007) and humans (Waters, 2008). 


\section{Mammary stem cells}

During puberty and gestation they provide the source of cells for the mammary gland growth. Liu et al., (2005) indicated that they play an important role in breast cancer and development of myoepithelial cells in the mammary gland.

\section{Plasticity of stem cells}

Plasticity of stem cells specifies their capacity to take possession of the characteristics of cells elsewhere in the body (Wagers and Weissman, 2004). For example, bone marrow stem cells have the ability to take possession and change to liver or lung cells.

\section{Potency of stem cells}

Potency indicates the ability to differentiate

Totipotent (totipotentia - Latin; Meaning in English - ability for all things)

Totipotent stem cells are those that can become any kind of cell in the body. 'Toti' originates from a Latin word which means whole or complete or total.

After the fertilization of an egg, it undergoes a series of divisions to become an embryo before turning into a foetus. The cells that are formed during the first few divisions are 'totipotent'.

The 'Morula' stage (16 cell stage) of the embryo is the best example of 'totipotent' cell. After 3 - 4 divisions of 'totipotent' cells, these cells will not be able to differentiate into any other cell type. Western (2009) reported that it is possible for a fully differentiated cell to return to the state of totipotency.

Pluripotent (pluripotentia - Latin; Meaning in English - ability for many things)
Pluripotent stem cells are those that have the ability to become almost any kind of cell in the body. Pluripotent stem cells result from totipotent stem cells after they have undergone first few divisions. Embryonic stem cells (Inner Cell Mass) at the blastocyst stage and fetal stem cells are pluripotent. Both toti and pluripotent cells are essential for the development of new organism; hence they are found in the early stages of development in the embryo.

Multipotent (potential to differentiate into discreet cell types)

These stem cells can differentiate into a number of cells. However, it is limited toa closely related family of cells. They are limited to mostly cells of the blood, heart, muscle and nerves. These cells function as a repair system for damaged tissues. The example in this category is Adult stem cells.

Oligopotent (potential to differentiate into few cell types)

They can differentiate into few cell types eg. Lymphoid and Myeloid cells

Unipotent (potential to differentiate into only one cell type)

These stem cells can produce only one cell type and have the property of self-renewal. This differentiates it from progenitor cells which cannot self-renew.

\section{Routes of transplantation of stem cells}

Autologous route of transplantation (AUTO transplant)

Source is the patient's own stem cells (autologous). They are either the cells from patient's own body or his or her cord blood. 
Nowadays, for autologous transplants physicians usually collect stem cells from the peripheral blood rather than the marrow. Gabrusiewicz et al., (2017) described the role of Myeloid derived suppressor cells (MDSCs) in Glioblastoma development (GBM), with a primary focus on potential therapeutic strategies.

\section{Allogeneic route of transplantation (ALLO transplant)}

Source of stem cells is another donor (allogeneic). They can be either a) Familial allogeneic (primarily relatives - parent, child, sister or brother) orb) Unrelated allogeneic (completely unrelated donors). The stem cells in this situation are extracted from either the donor's body or donor's cord blood (Umbilical cord transplant). Slavin et al., (1998) reported that myeloablative conditioning associated with hazardous immediate and late complications is considered as a mandatory first step in preparation for allogeneic blood or marrow transplantation (allogeneic BMT) for the treatment of malignant hematologic disorders and genetic diseases. Immunemediated graft-versus-leukaemia (GVL) effects constitute the major benefit of allogeneic BMT. They introduced the use of relatively non myeloablative conditioning before allogeneic BMT aiming for establishing host-versus-graft tolerance for engraftment of donor immune hematopoietic cells for induction of GVL effects to displace residual malignant or genetically abnormal host cells.

\section{Xenogeneic route of transplantation (XENO transplant)}

Source of stem cells is from different species. Striatal porcine fetal ventral mesencephalic (FVM) xenotransplants made for Parkinson's disease (Schumacher and Isacson, 1997). However lifelong immunosuppression and risk of rejection are the major limitations. Naito et al., (2004), found that undifferentiated mouse embryonic stem cell derived cardiomyocytes survived in normal myocardium after transplantation. They further suggested this to be an attractive strategy to treat heart diseases. Neimeyer et al., (2010) studied the xenogeneic transplantation of human mesenchymal stem cells.

\section{Applications of stem cells in livestock production}

The efficient use of stem cells has proved to bean essential tool in enhancing Livestock Reproduction. Stem cells are usedin various fields such as

Gene Targeting -Zwaka and Thomson (2003), reported an electroporation approach, based on the physical characteristics of human ES cells, that they used to successfully target HPRT1, the gene encoding hypoxanthine phosphoribosyltransferase-1 (HPRT1), and POU5F1, the gene encoding octamer-binding transcription factor 4 (Oct4; also known as POU domain, class 5, transcription factor 1 (POU5F1)

Animal Cloning - Where the combined action of young oocytes tends to form efficient development of bovine nuclear transfer embryos (Stice and Keefer, 1993),

Transgenic animal production (Saito et al., 2001), Chimera Animal Production (Cibelli et al., 1998),

Nuclear Transfer (Harrison et al., 2002) and

Genetic Engineering (Soto and Ross, 2016) Because of the competent use of stem cells in transgenic animal production, genetic enhancement of the livestock can be boosted (Wheeler, 2007). 


\section{Properties of Stem cell}

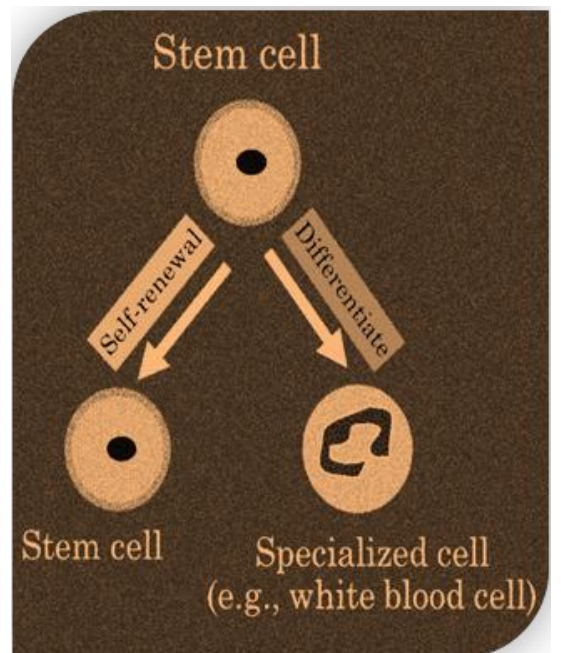

\section{ADULT STEM CELLS}

\section{Derived from adult body} organs

1. Bone Marrow

2. Adipose Tissue

3. Muscle

4. Nervous Tissue

5. Tendon

6. Dental Pulp

\section{EMBRYONIC STEM CELLS}

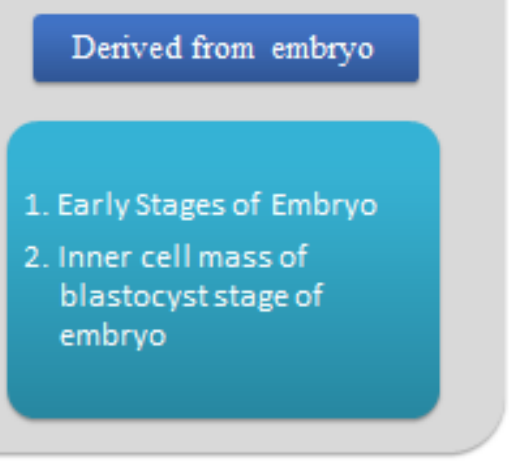

\begin{tabular}{|l|r|}
\hline \multicolumn{1}{|c|}{ POTENCY OF STEM CELLS } \\
\hline Totipotent & $\begin{array}{r}\text { All three germ layers } \\
\text { Ectoderm, Mesoderm, Endoderm with } \\
\text { Placenta }\end{array}$ \\
\hline Pluripotent & $\begin{array}{r}\text { All three germ layers } \\
\text { Ectoderm, Mesoderm, Endoderm }\end{array}$ \\
\hline Multipotent & Multiple cell types \\
\hline Unipotent & Single Cell Type \\
\hline
\end{tabular}

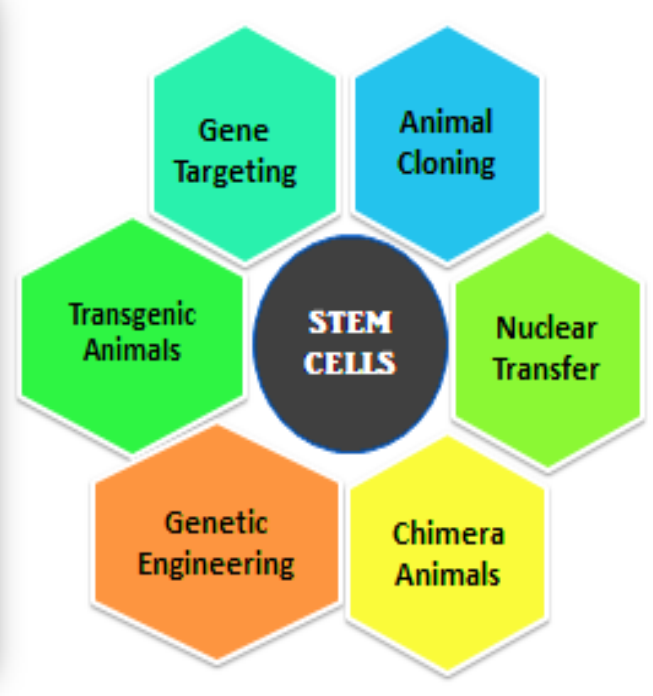




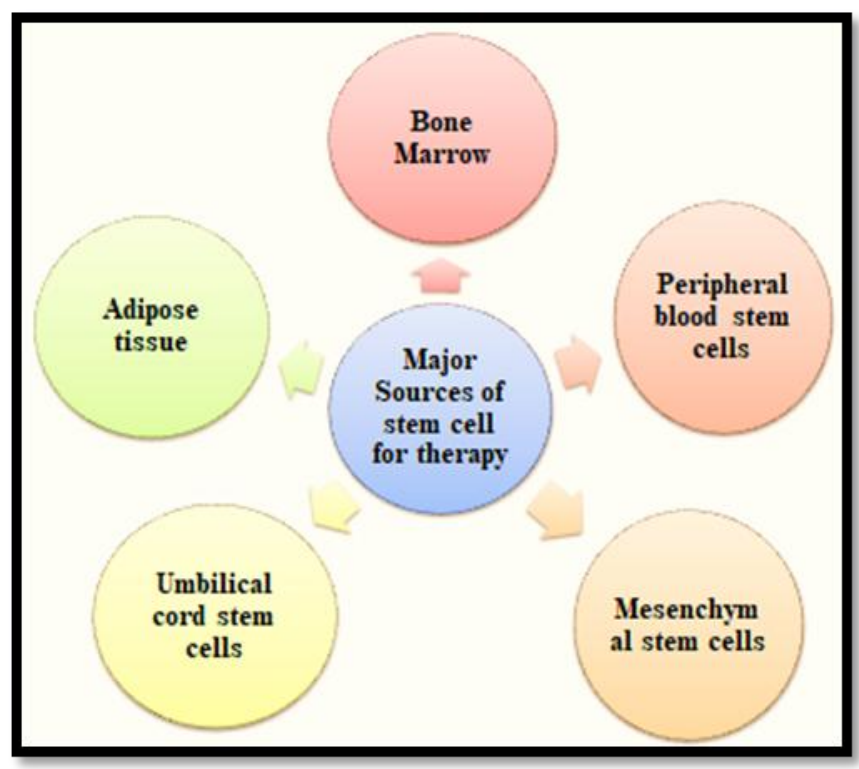

STEM CELLS IN THERAPEUTICS

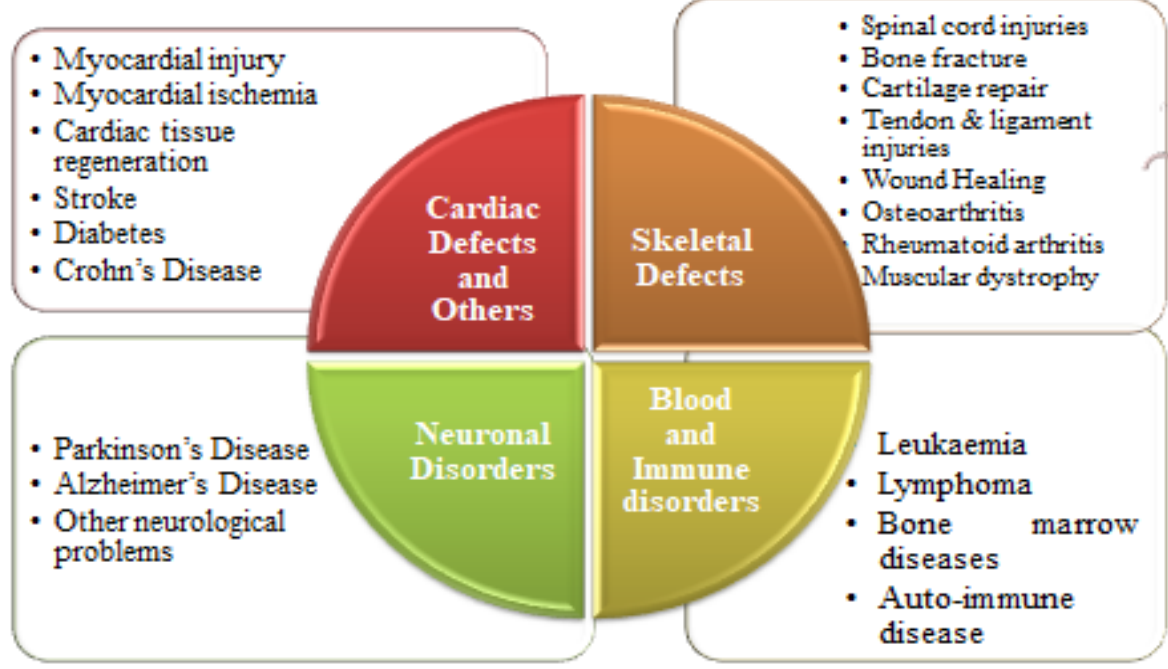

Foreign DNA is introduced into the animal, using recombinant DNA technology, and then must be transmitted through the germ line so that every cell, including germ cells, of the animal contains the same modified genetic material.

Stem cells also play an immense role in animal cloning where various somatic cells like fetal fibroblasts can be used for cloning (Yadav et al., 2005). This procedure begins with in vitro fertilization, the union of a sperm and an egg to generate a zygote outside the body. The zygote (from here onwards also called an embryo) divides into two and then four identical cells. At this stage, the cells can be separated and allowed to develop into separate but identical blastocysts, which can then be implanted in a uterus.

In case of Chimera animal production, Embryonic Stem (ES) cells are used conservatively to transform the germline, which is a greater practical claim in certain species of animal, which has a long generation interval. Chimeras are animals 
composed of cells that originate from two (or more) different species. In the research lab, chimeras are created by introducing cells from one species into the developing embryo or foetus of another. A sheep-goat chimera which was created by inner cell mass transplantation into ovine blastocysts, resulted in the offspring with the head of a goat and the woolly coat of a sheep (Polzin et al., 1987). Hatched chicks with chimeric brains containing cells from both the domestic chicken (Gallus gallusdomesticus) and the Japanese quail (Coturnix coturnixjaponica) (Chicken-quail chimeras) have been produced by transplantation of various regions of the neural tube at the 8- to 15- somite stage (Balaban et al., 1988). Because of the powerful function of ES cells, chimeras have become important tools for the study of cell lineage differentiation and embryogenesis.

Nuclear transfer (NT) technology now provides an alternative route for cell-based transgenesis in domestic species, offering new opportunities in genetic modification. In case of Nuclear Transfer Technique, somatic cells which are genetically targeted provides an alternative way in the production of knock out Porcine Foetal Fibroblasts which are deficient of $\alpha(1,3)$ galactosyl transferase ( $g a l \mathrm{~T}$ ) enzyme (Harrison et al., 2002). Stem cells also play an indispensible role in chemical or drug selection and screening. Stem cells characterize a vibrant system appropriate to the identification of innovative molecular targets and the improvement of unique drugs, which can be confirmed in vitro for safety or to estimate or forestall potential toxicity in humans (Davila et al., 2004).

Apart from this Stem cells can assist in conservation of germplasm of endangered species (Ben-nun et al., 2011). They reported the generation of induced pluripotent stem cells (iPSCs) in two endangered species includes Mandrillus leucophaeus and
Ceratotheriumsimumcottoni. Stem cell technology is being established in high producing animals such as buffaloes and cattle (Yadav et al., 2005; Anand et al., 2011; Kumar et al., 2011) and may possibly be used commendably for improving meat and milk production, in bio pharming of beneficial and therapeutic proteins, decline in greenhouse gases emanations and in- vitro production of meat (Niemann et al., 2011).

\section{Therapeutic applications of stem cells}

Stem cells are also utilized in Regenerative Therapy of Veterinary Medicine, because of their distinctive renewing potential. Stem cells can be employed in correcting various clinical conditions like Ligament Repair (Watanabe et al., 2002), Tendon Injury (Smith et al., 2003), Cardiac Defects (Min et al., 2003), Cartilage Defects (Xiang et al., 2006), Spinal injuries (Dasari et al., 2007), Bone Repair (Liu et al., 2010), Wound Healing (Lee et al., 2011; Azari 2011) and also for Testis Xenografting (Honaramooz et $a l .$, 2002). Stem cell therapy can be used for treatment of several diseases like Parkinson, cancer, myocardial infarction, defects in heart muscle cells or insulin-producing pancreatic cells, missing teeth, Crohn's disease, and leukaemia.

Stem cells can be genetically engineered to accomplish activities that they would not normally be programmed to do. This approach can be used to deliver the chemotherapeutic agents for treatment of cancers and tumours. $\mathrm{Hu}$ and $\mathrm{Fu}$ (2012) reported that understanding the basic characteristics of cancer stem cells will assist to develop novel therapies to eliminate the initiating cancer stem cell. Spinal injuries lead to loss of tissue, including myelinated fibre tracts responsible for carrying nerve impulses. Nervous tissue has limited regenerative capacity. Transplantation of stem cells which 
have the ability to differentiate into neurons and supporting cells helps in the recovery from spinal injuries. Teng et al., (2002) reported that unique polymer scaffold seeded with neural stem cells was used to treat traumatic spinal cord injury in animals.

Embryonic Stem Cells help to regenerate the severely dysfunctional myocardium and bring additional evidence for an immune privilege of these cells (Zhu et al., 2017). In a swine model of myocardial ischemia-reperfusion injury, the engraftement of pluripotent stem cells derived cardiac cells was used for the treatment of myocardial repair. Mesenchymal Stem Cells are used for the repair of cartilaginous tissue that is difficult to heal in adult animals. They differentiate into chondrogenic lineage and it is utilized to treat cartilage defects. Mesenchymal Stem Cells can also undergo osteogenic differentiation. Bruder et al., (1998) explored the potential for using autologous stem cell therapy to augment bone repair and regeneration. Cheng et al., (2015) studied the effects of Wharton's Jelly tissue transplantation to reduce traumatic brain injury and suggested it may have therapeutic potential.

In conclusion, Stem cells because of their extensive properties have got tremendous applications in both livestock production and therapeutics. Stem cells are considered to be the most promising factor for cell-based therapies. In the field of veterinary science, stem cells are mainly used for the treatment in canine and equines. However, the high expense in treatment restricts the use of stem cell therapy. Cost of stem cell therapy will be hopefully reduced, when extent of stem cell production is largely increased. Clinical use of stem cells requires various researches for standardization of desired treatment protocols, routes of administration and dosage. Stem cells can be also used to treat various chronic and irrecoverable conditions.

\section{References}

Altman, J. and Das, G.D. (1965). Autoradiographic and histological evidence of postnatal hippocampal neurogenesis in rats. The Journal of Comparative Neurology, 124 (3): 31935

Alvarez-Buylla, A., Seri, B., Doetsch, F. (2002). Identification of neural stem cells in the adult vertebrate brain. Brain Research Bulletin, 57 (6): 751-8

Anand, T., Kumar, D., Singh, M.K., Shah, R.A., Chauhan, M.S., Manik, R.S., Singla, S.K. and Palta, P. (2011).Buffalo Embryonic, Fetal and Adult Stem Cells: Progress and Challenges. Reproduction in Domestic Animals, 46: 50

Azari, O., Babaei, H., Derakhshanfar, A., Nematollahi-Mahani, S.N., Poursahebi, R. and Moshrefi, M. (2011). Effects of transplanted mesenchymal stem cells isolated from Wharton's jelly of caprine umbilical cord on cutaneous wound healing; histopathological evaluation. Veterinary Research Communications, 35: 211.

Balaban, E, Teillet, M. A, Le Douarin N. (1988). Application of the quail-chick chimera system to the study of brain development and behavior. Science, 241(4871):1339-42.

Barbara Miller. (2007). Testicles yield stem cells in science breakthrough. Australian Broadcasting Corporation, 20 September 2007

Ben-nun, I.F., Montague, S.C., Houck, M.L., Loring, J.F. (2011).Induced Pluripotent stem cells from highly endangered species. Nature Methods, 8(10):829-31

Bruder, S.P., Jaiswal, N., Ricalton, N.S., Mosca, J.D., Kraus, K.H., Kadiyala, S. (1998). Mesenchymal stem cells in osteobiology and applied bone 
regeneration.Clinical Orthopaedics and Related Research, (355): S247-56.

Cheng, T., Yang, B., Li, D., Ma, S., Tian, Y., Qu, R., Zhang, W., Zhang, Y., Hu, K., Guan, F., Wang, J. (2015). Wharton's Jelly Transplantation Improves Neurologic Function in a Rat Model of Traumatic Brain Injury. Cellular and Molecular Neurobiology, 35: 641-9.

Cibelli, J. B., Stice, S. L., Golueke, P. J., Kane, J. J., Jerry, J., Blackwell, C., de Leon, F. A. P and Robl, J. M. (1998). Transgenic bovine chimeric offspring produced from somatic cell- derived stem- like cells. Nature Biotechnology, 16: 642-646.

Dasari, V.R., Spomar, D.G., Gondi, C.S., Sloffer, C.A., Saving, K.L., Gujrati, M., Rao, J.S. and Dinh, D.H. (2007). Axonal remyelination by cord blood stem cells after spinal cord injury. Journal of Neurotrauma, 24:391-410

Davila, J.C., Cezar, G.G., Thiede, M., Strom, S., Miki, T. and Trosko, J. (2004). Use and application of stem cells in toxicology. Toxicological Sciences, 79: 214

Gabrusiewicz, K., Colwell, N.A. and Heimberger, A.B. (2017). The Role of Myeloid- Derived Suppressor Cells in Immunosuppression in Brain Tumors. Translational Immunotherapy of Brain Tumours, Pages 63-82 (Chapter 40).

Harrison, S. J., Guidolin, A., Faast. R., Crocker, L. A., Giannakis, C., d'Apice, A. J. F., Nottle, M. B. and Lyons, I. (2002). Efficient generation of $\alpha(1,3)$ galactosyltransferase knockout porcine fetal fibroblasts for nuclear transfer. Transgenic Research, 11: 143-150

Honaramooz, A., Snedaker, A., Boiani, M., Scholer, H., Dobrinski, I. and Schlatt, S. (2002). Sperm from neonatal mammalian testes grafted in mice. Nature, 418: 778
$\mathrm{Hu}, \mathrm{Y}$. and $\mathrm{Fu}, \mathrm{L}$. (2012).Targeting cancer stem cells: a new therapy to cure cancer patients. American Journal of Cancer Research, 2(3): 340-56

Kumar, D., Anand, T., Singh, K.P., Singh, M.K., Shah, R.A., Chauhan, M.S., Singla, S.K., Palta, P. and Manik, R.S. (2011). Derivation of buffalo embryonic stem-like cells from in-vitro produced blastocysts on homologous and heterologous feeder cells. Journal of Assisted Reproduction and Genetics, 28: 679

Lee, K.B., Choi, J., Cho, S.B., Chung, J.Y., Moon, E.S., Kim, N.S. and Han, H.J. (2011). Topical embryonic stem cells enhance wound healing in diabetic rats. Journal of Orthopaedic Research, 29:doi: 10.1002/jor.21385

Lewis, P.D. (1968). Mitotic activity in the primate subependymal layer and the genesis of gliomas. Nature, 217 (5132): 974-75

Liu, X., Li, X., Fan, Y., Zhang, G., Li, D., Dong, W., Sha, Z., Yu, X., Feng, Q., Cui, F., Watari, F. (2010). Repairing goat tibia segmental bone defect using scaffold cultured with mesenchymal stem cells. Journal of Biomedical Materials Research Part B: Applied Biomaterials, 94(1):44-52

Min, J., Yang, Y., Sullivan, M.F., Ke, Q., Converso, K.L., Chen, Y., Morgan, J.P. and Xiao, Y. (2003). Long-term improvement of cardiac function in rats after infarction by transplantation of embryonic stem cells. The Journal of Thoracic and Cardiovascular Surgery, 125:361-69

Naito, H., Nishizaki, K., Yoshikawa, M., Yamada, T., Satoh, H., Nagasaka, S., Kiji, T. and Taniguchi, S. (2004). Xenogeneic embryonic stem cellderived cardiomyocyte transplantation. Transplantation Proceedings, 36(8): 2507-08 
Niemann, H., Kuhla, B. and Flachowsky, G. (2011).Perspectives of feed-efficient animal production. Journal of Animal Sciences, 10.2527/ jas.2011-4235

Niemeyer, P., Schönberger, T. S., Hahn, J., Kasten, P., Fellenberg, J., Suedkamp, N., Mehlhorn, A.T., Milz,S. and Pearce, S. (2010). Xenogeneic transplantation of human mesenchymal stem cells in a critical size defect of the sheep tibia for bone regeneration.Tissue Engineering Part A, 16(1):33-43

Polzin, V. J, Anderson, D. L, Anderson, G. B, BonDurant, R. H, Butler, J. E, Pashen, R. L, Penedo, M. C, Rowe, J. D. (1987). Production of sheep-goat chimeras by inner cell mass transplantation. Journal of Animal sciences, 65(1): 325-30.

Saito, M., Iwawaki, T., Taya, C., Yonekawa, H., Noda, M., Inui, Y., Mekada, E., Kimata, Y., Tsuru, A. and Kohno, K. (2001).Diphtheria toxin receptormediated conditional and targeted cell ablation in transgenic mice. Nature Biotechnology, 19:746-50

Schumacher, J. M. and Isacson, O. (1997). Neuronal xenotransplantation in Parkinson's Disease. Nature Medicine, 3:474-75

Slavin,S., Nagler,A., Naparstek, E., Kapelush nik,Y., Aker,M.,Cividalli,G.,Varadi,G., Kirschbaum,M., Ackerstein,A., Samuel, S., Amar, A., Brautbar, C., Ben-Tal, O., Eldor, A. and Or, R. (1998). Nonmyeloablative Stem Cell Transplantation and Cell Therapy as an Alternative to Conventional Bone Marrow Transplantation With Lethal Cytoreduction for the Treatment of Malignant and Nonmalignant Hematologic Diseases. Blood, 91; 756-63

Smith, R.K.W., Korada, M., Blunn, G.W. and Goodship, A.E. (2003). Isolation and implantation of autologous equine mesenchymal stem cells from bone marrow into superficial digital flexor tendon as a potential novel treatment. Equine Veterinary Journal, 35(1):99102

Soto, D. A. and Ross, P. J. (2016). Pluripotent stem cells and livestock genetic engineering. Transgenic Research, 25: 289-306

Stice, S.L. and Keefer, C.L. (1993). Multiple generational bovine embryo cloning. Biology of Reproduction, 48: 715-19

Teng, Y.D., Lavik, E.B., Qu, X., Park, I.Q., Ourednik, J., Zurakowski, D., Langer, R. and Snyder, E.Y. (2002).Functional recovery following traumatic spinal cord injury mediated by a unique polymer scaffold seeded with neural stem cells. Proceedings of the National Academy of Sciences of the United States of America, 99(5) 3024-29

Wagers, A.J. and Weissman, I. L. (2004). Plasticity of Adult Stem Cells. Cell, 116(5): 639-48

Watanabe, N., Woo, S.L.Y., Papageorgiou, C., Celechovsky, C. and Takai, S. (2002).Fate of Donor Bone Marrow Cells in Medial Collateral Ligament after Simulated Autologous Transplantation. Microscopy Research and Technique, 58(1):39-44

Waters, R. (2008). Testicle Stem Cells Become Bone, Muscle in German Experiments. Bloomberg, 8 October 2008

Western, P. (2009). Foetal germ cells: striking the balance between pluripotency and differentiation. International Journal of Developmental Biology, 53 (2-3): 393409

Wheeler, M. B. (2007). Agricultural applications of transgenic livestock.Trends in Biotechnology. 25(5): 204-10

Xiang, Z., Hu, W., Kong, Q., Zhou, H. and Zhang, X. (2006). Preliminary study of mesenchymal stem cells-seeded type I 
collagen-glycosaminoglycan matrices for cartilage repair. Zhongguo Xiu Fu Chong JianWaiKeZaZhi, 20(2):148-54

Yadav, P.S., Kues, W.A., Herrmann, D., Carnwath, J.W. and Niemann, H. (2005). Bovine ICM derived cells express the Oct4 ortholog. Mol. Reprod. Dev., 72: 182
Zhu, W., Gao, L. and Zhang, J. (2017). Pluripotent Stem Cell Derived Cardiac Cells for Myocardial Repair. Journal of Visualized Experiments, 3; 120, doi: $10.3791 / 55142$

Zwaka, T.P. and Thomson, J.A. (2003). Homologous recombination in human embryonic stem cells. Nature Biotechnology, 3:319-21

\section{How to cite this article:}

Kennady Vijayalakshmy, Ninan Jacob, Dharmendra Kumar, Meenakshi Virmani, Naresh Selokar Lalaji and Yadav, P.S. 2018. Potential Applications of Stem Cells in Livestock Production. Int.J.Curr.Microbiol.App.Sci. 7(03): 67-77. doi: https://doi.org/10.20546/ijcmas.2018.703.008 